\title{
Linking phytoavailability of inorganic nanoparticles with their transformation in the rhizosphere
}

\author{
SONIA MORAIS RODRIGUES ${ }^{1}$, SANDRA RODRIGUES ${ }^{2}$, \\ MATHEUS MIRANDA $^{1}$, NATÉRCIA MARTINS ${ }^{2}$, TITO \\ TRINDADE $^{2}$, XIAOYU GAO ${ }^{3}$, GREGORY V. LOWRY ${ }^{3}$ AND \\ ASTRID AVELLAN ${ }^{1}$ \\ ${ }^{1}$ Universidade de Aveiro \\ ${ }^{2}$ University of Aveiro \\ ${ }^{3}$ Carnegie Mellon University \\ Presenting Author: smorais@ua.pt
}

To implement an environmentally safe use of nano-enabled products in agriculture, there is a need to understand processes regulating the fate of nanoparticles in natural media like soil. Upon soil deposition, a number of transformations occur depending on biogeochemical conditions that control fate, and phytoavailability of NPs in soil and pore water[1]. These transformations will be different in bulk soil in comparison to rhizosphere soils, where chemicals released by roots and microorganisms modulate NP reactions. These will ultimately regulate NPs impacts toward the organisms of the rhizosphere, along with root adsorption and uptake.

Here we will discuss localized changes in biogeochemical conditions resulting from biological activity at the rhizosphere as drivers for short-term kinetic reactions and increased phytoavailability of metal ions dissolved from inorganic NPs. A key relevant aspect which is often overlooked is the interaction between NPs and plants, notably enhanced chemical exudation due to the presence of NPs at the root-soil interface.

Results from three of our recent studies will be presented to this aim. Martins et al[2] focused on the application of composites of biopolymers and $\mathrm{ZnO}$ NPs for controlled release of ionic $\mathrm{Zn}$ in agricultural soils. Clearly, maize exudates controlled $\mathrm{ZnONPs}$ dissolution and $\mathrm{Zn}$ bioavailability in the soil under maize-root influence. The observed elevation of $\mathrm{pH}$ in the roots vicinity was attributed to the plant response to a (too) high bioavailable Zn concentration. Secondly, we will discuss the role of wheat exudates to increase soluble $\mathrm{Cu}$ in pore water and alter the $\mathrm{Cu}$ ion exposure profile in the rhizosphere compared to bulk soil [3]. Here $\mathrm{Cu}$ toxicity to wheat was observed as a response to ionic $\mathrm{Cu}$ (either in $\mathrm{CuSO} 4$ treatment or upon CuONPs dissolution in the rhizosphere), and not as a response to the presence of CuONPs. Finally, we will discuss the effect of soil properties and of a PVP polymer coating on the geochemical distribution of AgNPs added to soil planted with lettuce as well as inhibitory effects on enzymatic activities of five soil exoenzymes related to nutrient cycles ( $\beta$-glucosidase, cellulase, acid phosphatase, protease and urease) (Cruz et al., submitted). 